\title{
Utilizing an Intervention Forecasting Approach to Improve Reefer Container Demand Forecasting Accuracy: A Case Study in Indonesia
}

\author{
Sintia Putri Pradita ${ }^{1}$, Pornthipa Ongkunaruk ${ }^{1 *}$, Thaweephan (Duke) Leingpibul ${ }^{2}$ \\ ${ }^{1}$ Department of Agro-Industrial Technology, Faculty of Agro-Industry, Kasetsart University, 50 Ngam Wong \\ Wan Rd. Lad Yao, Chatuchak, Bangkok 10900, Thailand \\ ${ }^{2}$ Haworth College of Business, Western Michigan University, 1903 Western Michigan Avenue Kalamazoo, MI \\ 49008, USA
}

\begin{abstract}
The demand for reefer containers in Indonesia has been increasing due to both global and regional trade growth; however, logistics providers are still struggling with several related challenges, including a container shortage problem, which is due to ineffective forecasting practices. This study aimed to improve the accuracy of reefer container demand forecasting by introducing an intervention forecasting approach. This approach will help address the demand planning issue of reefer circulation. The intervention forecasting approach combines human insights from the qualitative approach with the mathematical precision of the quantitative approach in iterative sequences. This field study was conducted with an Indonesian third party logistic company in Eastern Indonesia. The training data set was analyzed to provide a pattern of demand as well as some initial forecasting parameters (such as trend and seasonal index). Then, an expert helped identify irregular demand points. The demand data was then adjusted by a sales and marketing manager according to related factors such as natural disasters, oil price increase, promotions. The selected models were then further verified using a testing dataset, and the forecast errors from various models using the raw and adjusted training data sets were compared with those of the testing datasets. The results revealed that the mean average percentage error (MAPE) after adjusting the demand was $5.43 \%$ to $6.22 \%$ for the training and $9.55 \%$ to $10.33 \%$ for the testing dataset, which is lower than that of the traditional forecasting method when there was no intervention. In summary, the adjustment forecast could increase forecast accuracy by $42.39 \%$ and $39.42 \%$ for 20 - and 40 -feet containers, respectively.
\end{abstract}

Keywords: Intervention; Qualitative forecasting method; Reefer containers; Third party logistics providers; Time series forecasting

\section{Introduction}

The growth of container use in marine transportation has steadily increased in recent years due to economic development in Asia (Diaz et al., 2011). As the world's largest archipelagic country, the distribution of agricultural and food products in Indonesia is normally conducted through sea transportation (BPS-Statistics Indonesia, 2018). According to the Indonesia Cold Chain Association, the number of logistics providers in Indonesia is still growing, especially third party logistics providers (3PLs), who provide shipping services with reefer containers (Gandi, 2016). The delivery of food products is 
carried out from Java to Eastern Indonesia using temperature control to maintain product quality. However, the accumulation and repositioning of empty containers have become major issues for container ports and could be worsened by the growing trade imbalances emerging among trading routes. Having too many emptied containers in certain locations is an indicator of other planning issues in the shipping business (Epstein et al., 2012), the first of which is an imbalance in container demand among different regions. The second problem is multiple sources of uncertainty, such as market conditions, and the third problem relates to the handling and sharing of operations information. These problems affect every third party logistics provider, increasing their operational costs as well as creating a shortage of containers and reducing their income (Pradita and Ongkunaruk, 2019). Previous research on container demand forecasting in the area of reefer containers has been as follows: Wang and Meng (2019) compared three forecasting models for the number of inbound of containers, while Tang et al. (2019) studied container throughput forecasting at Lianyungang Port and Shanghai Port by comparing the Gray model, triple exponential smoothing model, multiple linear regression model, and backpropagation neural network. Tangkham and Ongkunaruk (2019) suggested the container yard to establish a proper forecasting method for demand for containers in Thailand. In addition, Mo et al. (2018) studied container throughput forecasting using the group method of data handling (GMDH) neural network. They also studied a hybrid forecasting model (SARIMA), support vector regression (SVR), back-propagation (BP) neural network, and genetic programming (GP). There are two major forecasting methods. First, the qualitative forecasting method is analyzed based on the opinions, judgments, and past performance of forecasting experts (Arvan et al., 2019). The factors that influence demands for commercial products are sales promotions, the introduction of a new brand, store reform, and aggressive marketing (Meneghini et al., 2018). The type of qualitative forecasting using an expert adjustment or intervention is more appropriate when demand is highly sensitive to sales promotion (Min, 2008; Trapero et al., 2015; Fildes et al., 2019). Furthermore, online marketing demand prediction based on user/consumer reviews and promotional marketing using bigdata was investigated by Chong et al. (2017). The higher the forecast accuracy, the more the bullwhip effect is reduced (Jaipuria and Mahapatra, 2014). While qualitative forecasting is only used when the amount of historical data is limited, quantitative forecasting is more commonly used among practitioners. The types of most commonly used quantitative forecasting are time series, regression model (Taylor and Letham, 2018), Autoregressive Integrated Moving Average (ARIMA) (Min, 2008; Jaipuria and Mahapatra, 2014; Dhini, 2015), Seasonal Autoregressive Integrated Moving Average (SARIMA) (Farhan and Ong, 2018; Mo et al., 2018), Artificial Neural Network (ANN) (Jaipuria and Mahapatra, 2014; Dhini et al., 2015); and Multinomial Logit Model (MNL) (Lubis et al., 2019). In circumstances of promotion or irrational events, combining qualitative and quantitative methods could be implemented to increase forecast accuracy (Min, 2008; Jaipuria and Mahapatra, 2014; Khamphinit and Ongkunaruk, 2016; Chong et al., 2017). We hypothesized that the intervention forecasting approach would provide better forecasting accuracy than other time series alternatives, such as ARIMA and SRIMA. The primary advantage of the aforementioned techniques (i.e. $\mathrm{BP}, \mathrm{SVM}, \mathrm{ANN}$ ) is a high mathematical precision; however, the disadvantages of calculation complexity and intensive data requirements deter practitioners from utilizing these techniques. In contrast, the time series technique requires less data to operate and is intuitively simple, yet it still provides an acceptable level of mathematical precision. Therefore, the time series technique was selected for use in this study. Moreover, the experience level of the forecasters will affect the results of their forecasting: the greater the forecaster's expertise, the greater the adjustment will correctly represent the real insights 
and improve forecast accuracy (Trapero et al., 2015; Arvan et al., 2019; Fildes et al., 2019). The combination of qualitative forecasting via the adjustment of sales data by experts as well as quantitative forecasting via time series using a software package could increase forecast accuracy by $46.14 \%, 22.53 \%$, and $56.42 \%$ for three kinds of instant noodle products (Khamphinit and Ongkunaruk, 2016). Therefore, the intervention forecast method would perform well within the reefer circulation context, as in the present Indonesian 3PL case.

\section{Methods}

This case study was conducted at a third party logistics company that specializes in transportation and is located in Surabaya, East Java, Indonesia. The company was quite familiar with the researchers due to past project partnerships and thus felt comfortable sharing their internal/confidential supply chain issues (Pradita and Ongkunaruk, 2019). Based on an in-depth interview with Indonesian practitioners, poor forecasting practices were found to play a significant role in reefer circulation issues. One root cause of this poor forecasting stemmed from the use of an inappropriate forecasting practice that disregards data justification during the forecasting process (Khamphinit and Ongkunaruk, 2016). This study tried to improve forecasting accuracy by introducing a combination approach called intervention forecasting. This strategic forecasting practice combines the strengths of both quantitative and qualitative approaches to help improve forecasting accuracy. The qualitative approach uses human insight to help justify abnormal data points and adjusts them before using the quantitative approach to define the forecasting components mathematically. Hence, our objective was to improve the forecast accuracy of the demand for 20 -feet and 40-feet containers by comparing quantitative and intervention forecasting methods. Historical demand data was collected from 2016 to 2018, covering irregular events such as demand during a national disaster, shortages of containers in a depot, and projects from the Ministry of Marine Affairs and Fisheries Indonesia. The data was used in both the intervention forecasting approach and in the traditional quantitative time series approach as a comparison. The selected forecasting accuracy indicator (MAPE) of each approach was produced and compared. The key issue when evaluating a forecasting method is to measure the forecast accuracy (Davydenko and Fildes, 2013), as it is very important to a company's efficiency planning and inventory control (Box et al., 2008).

From 2016 to 2018, three years of historical demand data on the monthly container usage of 20 -feet and 40-feet containers was collected. Then, we separated the data into two groups: a training dataset and a testing data set. The first data set used $66.67 \%$ of the total data for the construction of the model, and the second dataset used 33.34\% of the total data and used the latest data for model validation (Meneghini et al., 2018). Therefore, the data were divided into two groups: a training dataset, composed of the first 24 months (2016 to 2017), to establish the best forecasting model and a testing dataset, composed of the last 12 months (2018), to validate the forecasting model with the actual data. Then, a graph was plotted to analyze the data pattern and identify the factors affecting the demand. Next, the best forecasting method was determined by the prediction function in the Crystal Ball software for both a training dataset (M) and adjusted training dataset (C). Our forecasting methods were ten time series methods as follows: Single Exponential Smoothing, Single Moving Average, Double Exponential Smoothing, Double Moving Average, Seasonal Additive, Seasonal Multiplicative, Holt-Winters' Additive, Holt-Winters' Multiplicative, ARIMA, and SARIMA. Forecasting error was measured by the Mean Absolute Percentage Error (MAPE) so we could easily compare the proportional values of the forecast error between the 20- and 40-feet containers, as shown in Equation 1 (Box et al., 2008). MAPE is normally used in inventory control problems like empty container repositioning. Later, the 
training datasets from 2016 and 2017 were adjusted by a sales and marketing manager to remove any irrational events that occurred. This was called an intervention, and the adjusted training dataset (C) was used to construct the best forecasting method, which was similar to the previous step. Then, we compared the forecast error when there was no intervention (M) and when there was an intervention of the training datasets $(\mathrm{C})$. The adjustment to the actual demand data in the training dataset was implemented based on the demand distortion pattern (Khamphinit and Ongkunaruk, 2016). If the demand was too high, we adjusted the demand through reduction. On the other hand, if the actual demand was too low, we adjusted the demand by increasing it. Later, the forecasted data of the adjusted training dataset was adjusted based on the events that occurred in 2018 (I). The forecast results were adjusted, since there were irregular events that occurred in 2018, such as national disasters and spontaneous projects from the government. Finally, we compared the forecast error between the actual data from 2018 and the best forecasting method of the training dataset (A). We then compared the actual 2018 data with the adjusted forecast (I) and analyzed the results.

$$
M A P E_{n}=\frac{\sum_{t=1}^{n}\left|\frac{E_{t}}{D_{t}}\right| 100}{n}
$$

The forecast error for period $\mathrm{t}$ is given by $E_{t}$, where the following holds: $E_{t}=F_{t}-D_{t}$ where $\mathrm{Ft}$ is the forecast at time $t, D_{t}$ is the demand at time $\mathrm{t}$, and $\mathrm{n}$ is the amount of data. A flow chart of the methodology is illustrated in Figure 1.

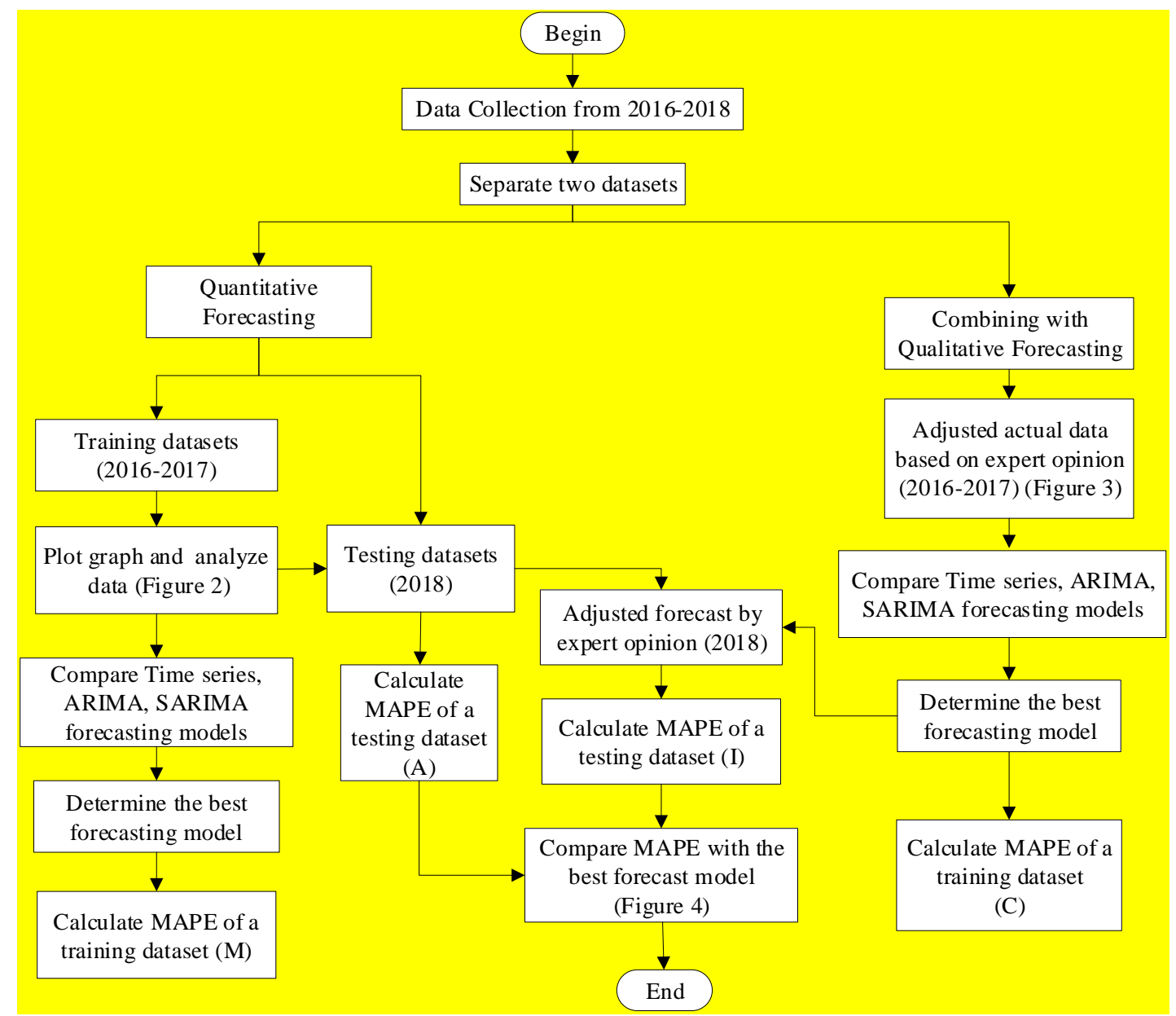

Figure 1 Flow chart of forecasting methodology 


\section{Results and Discussion}

\subsection{Historical Demand Data for 20-feet and 40-feet Containers}

The demand for 20-feet containers exhibited seasonality in the historical data, as shown in Figure 2. This means it possesses a seasonal pattern, with an increasing trend in the first quarter of each year. Specifically, demand increased one month (May) before the fasting month in June, declined during the Eid Al-Fitr holidays since there is no cargo shipping activity during this time, and increased again after Eid Al-Fitr. In the fourth quarter, the demand for 20-feet containers tended to be constant, as shown in Figure 2a. Additionally, the number of 40 -feet containers was less than the number of 20 -feet containers, because 40-feet containers are normally used for exportation. Likewise, 40 -feet containers also exhibit the same demand pattern during Ramadhan and Eid Al-Fitr holidays, as shown in Figure $2 \mathrm{~b}$. The Ramadhan month lasts 29 to 30 days depending on the sightings of the crescent moon that usually appears between May and June each year. The Eid Al-Fitr was held at the beginning of July in 2016 and in June for 2017 and 2018. Eid holidays are held for approximately two weeks, one week before Eid Al-Fitr and one week after Eid AlFitr. As a result, all logistics activities also declined during the holidays. After the Eid Al-Fitr holidays, the demand for reefer containers increased irregularly due to a retailer stock shortage. Therefore, the demand during Ramadhan was not adjusted, since, in this case, it was a seasonal pattern.

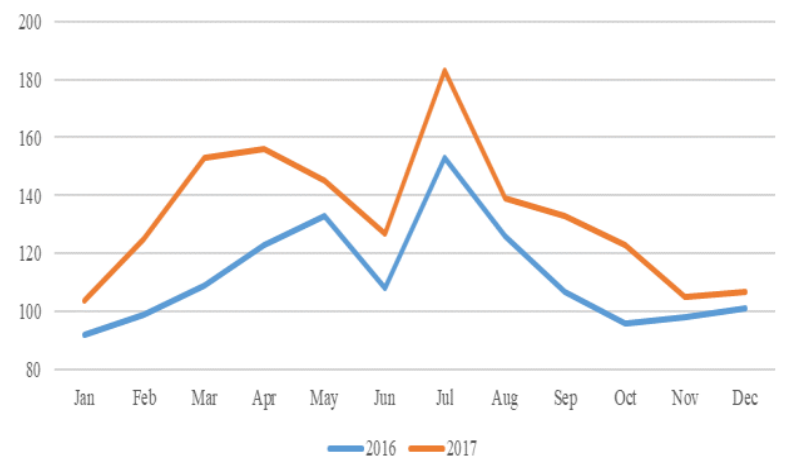

(a)

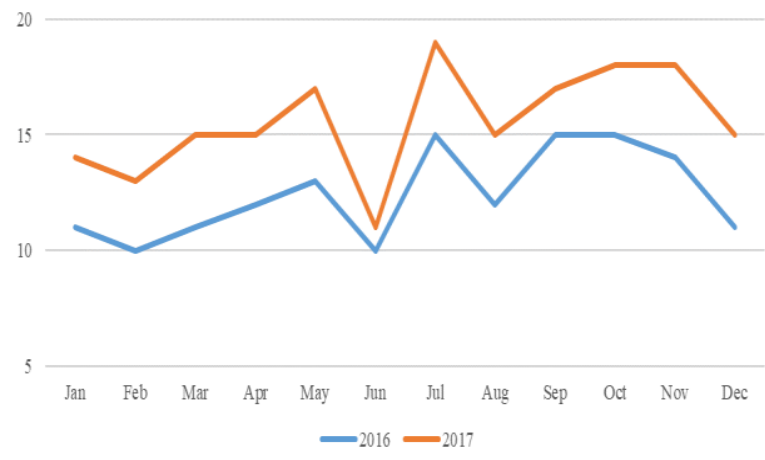

(b)

Figure 2 The historical demand data of: (a) 20-feet; and (b) 40-feet reefer containers

\subsection{Adjustment of Monthly Historical Demand and Intervention in Demand Forecasting}

The irregular events and the ways in which to adjust the actual data were analyzed by conducting an in-depth interview with a senior sales manager (Table 1). There are two major factors that drive irregular events, namely, internal factors and external factors. Internal factors in the supply chain are any factors that are due to suppliers, companies, or customers, while natural disasters, government policy, and regulation, society, and economic conditions are external factors (Khamphinit and Ongkunaruk, 2016).

Some natural disasters, such as the massive flooding in Gorontalo (Sulawesi island) in September to October 2016, occurred in Eastern Indonesia. Thus, the delivery of food supplies from Java was carried out to meet the needs of disaster victims in the Eastern region of Indonesia. As a result, demand for containers increased during this time; however, natural disasters are unpredictable, so the adjustment of the actual data was required to disregard the impact of abnormality. At present, the supply-demand for the company's containers is imbalanced, and it usually stores several containers outside its Java branches, with only a few containers that can be directly returned to the depot in Surabaya, East Java. This results in a shortage of containers. Thus, demand during such shortages was adjusted to eliminate the mismanaged storage of containers. 
Table 1 Adjustment of monthly historical demand data

\begin{tabular}{|c|c|c|c|c|c|}
\hline \multirow[t]{2}{*}{ No. } & \multicolumn{2}{|c|}{$\begin{array}{c}\text { Type of } \\
\text { container }\end{array}$} & \multirow[t]{2}{*}{ Time } & \multirow{2}{*}{$\begin{array}{l}\text { The adjustment } \\
\text { from the actual } \\
\text { demand }\end{array}$} & \multirow[t]{2}{*}{ Reason } \\
\hline & $20 \mathrm{ft}$ & $40 \mathrm{ft}$ & & & \\
\hline 1 & $\checkmark$ & & Oct 2016 & $5 \%$ & $\begin{array}{l}\text { Demand decreasing due to } \\
\text { supply shortage in the depot }\end{array}$ \\
\hline 2 & $\checkmark$ & & Feb-Apr 2017 & $-12 \%$ & $\begin{array}{l}\text { Demand increasing due to } \\
\text { projects at Papua and Sulawesi* }\end{array}$ \\
\hline 3 & $\checkmark$ & & Sep-Oct 2017 & $-10 \%$ & $\begin{array}{l}\text { Demand increasing due to } \\
\text { projects at Maluku and North } \\
\text { Maluku* }^{*}\end{array}$ \\
\hline 4 & $\checkmark$ & & Nov-Dec 2017 & $10 \%$ & $\begin{array}{l}\text { Demand increasing due to } \\
\text { capacity expansion }\end{array}$ \\
\hline 5 & & $\checkmark$ & Sep-Oct 2016 & $-5 \%$ & $\begin{array}{l}\text { Demand increasing due to a } \\
\text { large floods in Sulawesi }\end{array}$ \\
\hline 6 & & $\checkmark$ & Jan 2017 & $10 \%$ & $\begin{array}{l}\text { Demand increasing due to } \\
\text { capacity expansion }\end{array}$ \\
\hline 7 & & $\checkmark$ & Jun 2017 & $5 \%$ & $\begin{array}{l}\text { Demand decreasing due to } \\
\text { supply shortages in the depot }\end{array}$ \\
\hline
\end{tabular}

*Note: Projects came from the Ministry of Marine Affairs and Fisheries Indonesia

In early 2017, the company increased its inventory of 40 -feet containers and expanded its capacity. Later, in the same year, it expanded its capacity to include 20 -feet containers. Hence, actual demand during that time had to be adjusted to reduce the effects of excess supply containers.

The company has cooperated with the Ministry of Marine Affairs and Fisheries Republic Indonesia on several fisheries projects in Eastern Indonesia since 2017. As a maritime country, a reefer container is needed to transport captured fish from Eastern Indonesia to Java to facilitate processing or exportation. The fishing season occurs from February to April each year on the islands of Papua and Sulawesi, and the harvest season occurs from September to October each year on the Maluku and North Maluku islands (Talib, 2017). Demand during the fishing season in 2016-2018 was extremely high; thus it had to be adjusted to remove the effects. The adjusted demand amount was based on the fish production data of each region. For the government projects, the company used 20-feet containers in 2017 and 40-feet containers in 2018. Furthermore, fish production on the Papua and Sulawesi islands was higher than that on the Maluku and North Maluku islands; so, the adjusted demand was greater from February to April. A comparison between the actual demand and adjusted demand for 20 -feet and 40 -feet containers is shown in Figure 3.

Then, the forecasting results from the adjusted demand data were intervened by experts to eliminate the effects of irregular events that occurred in 2018. Intervention in demand forecasting means refers to experts adjusting the actual demand data based on irregular events, and the forecasting results from the Crystal Ball software being intervened based on expert's inputs. The intervention on demand forecasting was needed, since we already knew there were several irregular events that occurred in 2018. Specifically, there were two natural disasters, namely, the earthquake on Lombok island in August 2018 and the earthquake and tsunami in Donggala-Palu (Sulawesi island) in September 2018. In addition, there were several projects from the government during this time, which resulted in an increase in the actual demand for the containers. Overall, the results of the forecasted demand were lower than those of the actual demand; therefore, an intervention in the 
forecast result was implemented, based on expert opinion, by increasing the demand forecast to improve the forecasting accuracy, as shown in Table 2. Hence, this intervention of the forecast results was used to validate the actual data.

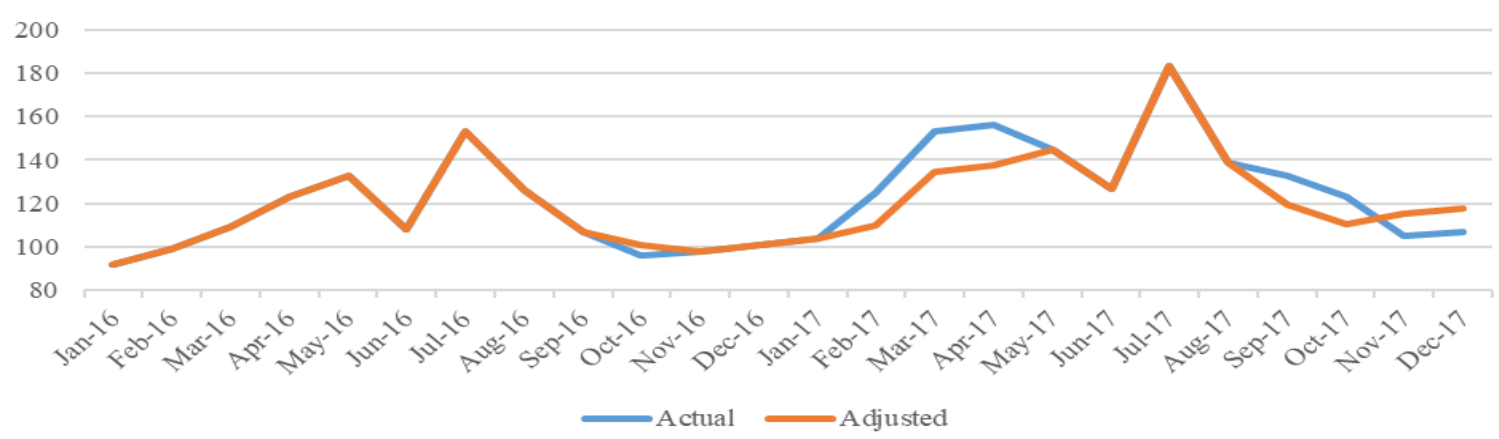

(a)

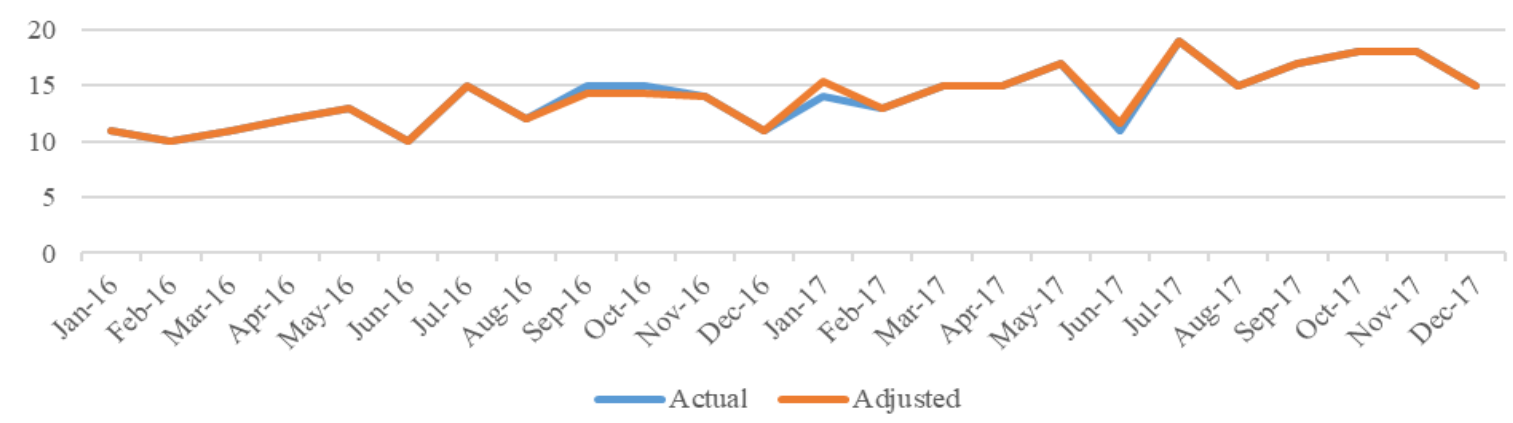

(b)

Figure 3 Actual and adjusted monthly demand data of: (a) 20-feet; and (b) 40-feet reefer containers

Table 2 Intervention in demand forecasting for 2018

\begin{tabular}{cccccl}
\hline \multirow{2}{*}{ No. } & \multicolumn{2}{c}{$\begin{array}{c}\text { Type of } \\
\text { container }\end{array}$} & Time & $\begin{array}{c}\text { Intervention in the } \\
\text { demand forecast }\end{array}$ & Reason \\
\cline { 2 - 3 } & $20 \mathrm{ft}$ & $40 \mathrm{ft}$ & & $5 \%$ & $\begin{array}{l}\text { Demand increasing due to Lombok } \\
\text { earthquake and Donggala Palu tsunami } \\
\text { Demand increasing due to project in }\end{array}$ \\
\hline 1 & $\checkmark$ & & Aug-Sep 2018 & $12 \%$ & $\begin{array}{l}\text { Papua and Sulawesi* } \\
\text { Demand increasing due to project in } \\
\text { Maluku and North Maluku* }\end{array}$ \\
\hline
\end{tabular}

*Note: Projects came from the Ministry of Marine Affairs and Fisheries Indonesia

\subsection{Comparison of Actual and Adjusted Forecasting Methods}

Pattern analysis showed that the 20 -feet containers exhibited a seasonal pattern, while the 40-feet containers exhibited a trend and seasonal pattern, as shown in Figure 2, which features two parallel graphs. Based on the lowest MAPE value shown in Table 4, the best time series forecasting method was Seasonal Additive and Holt-Winter's Additive for the 20 -feet and 40-feet containers, respectively, as shown in Table 3.

The forecast errors in the training dataset for non-adjusted demand (M) were $9.04 \%$ for the 20 -feet containers and $8.27 \%$ for the 40 -feet containers. Both testing datasets exhibited higher forecasting errors when compared to the training datasets. 
Table 3 The best time series forecasting method

\begin{tabular}{ccccc}
\hline \multirow{2}{*}{$\begin{array}{c}\text { Type of } \\
\text { container }\end{array}$} & Trend & Seasonal & $\begin{array}{c}\text { Non-adjusted } \\
\text { Demand }\end{array}$ & $\begin{array}{c}\text { Adjusted } \\
\text { demand }\end{array}$ \\
\cline { 2 - 5 } $20 \mathrm{ft}$ & & $\checkmark$ & \multicolumn{2}{c}{ Seasonal Additive } \\
$40 \mathrm{ft}$ & $\checkmark$ & $\checkmark$ & Holt-Winter's Additive \\
\hline
\end{tabular}

The forecast errors of the testing dataset before the demand adjustment (A) were $16.58 \%$ and $17.05 \%$ for the 20 -feet and 40 -feet containers, respectively; however, after adjusting the demand data, the forecasting errors of the training datasets (C) were $5.43 \%$ for the 20 -feet containers and $6.22 \%$ for 40 -feet containers. The forecast error of the testing datasets after demand adjustment (I) was $9.55 \%$ and $10.33 \%$ for the 20 -feet and 40 feet containers, respectively. It is common for a forecast error in a testing dataset to be higher than that in a training dataset, since the forecasting model is based on training datasets. When compared overall to both container sizes, non-adjusted demand exhibited a higher forecasting error when compared to the adjusted demand for both groups of data. As a result, the experts' adjustment helped increase the forecast accuracy anywhere from $24.87 \%$ to $42.39 \%$, as shown in Table 4 . This would be beneficial to the company in terms of container procurement planning and service level enhancement.

Table 4 Comparison in forecasting errors between regular forecast and intervention forecast

\begin{tabular}{|c|c|c|c|c|c|c|}
\hline \multirow{3}{*}{$\begin{array}{l}\text { Type of } \\
\text { container }\end{array}$} & \multicolumn{4}{|c|}{ Forecast accuracy by MAPE (\%) } & \multicolumn{2}{|c|}{$\%$ Forecast accuracy improvement } \\
\hline & \multicolumn{2}{|c|}{ Non-adjusted demand } & \multicolumn{2}{|c|}{ Intervention } & \multirow[b]{2}{*}{$\begin{array}{l}\text { Training data } \\
\left(100^{*}(\mathrm{M}-\mathrm{C}) / \mathrm{M}\right)\end{array}$} & \multirow[b]{2}{*}{$\begin{array}{l}\text { Testing data } \\
\left(100^{*}(\mathrm{~A}-\mathrm{I}) / \mathrm{A}\right)\end{array}$} \\
\hline & $\begin{array}{l}\text { Training data } \\
\left(\mathrm{M}^{*}\right)\end{array}$ & $\begin{array}{l}\text { Testing } \\
\text { data }\left(\mathrm{A}^{*}\right)\end{array}$ & $\begin{array}{l}\text { Training } \\
\text { data }\left(C^{*}\right)\end{array}$ & $\begin{array}{l}\text { Testing } \\
\text { data }\left(I^{*}\right)\end{array}$ & & \\
\hline $20 \mathrm{ft}$ & 9.04 & 16.58 & 5.43 & 9.55 & 39.95 & 42.39 \\
\hline $40 \mathrm{ft}$ & 8.27 & 17.05 & 6.22 & 10.33 & 24.87 & 39.42 \\
\hline
\end{tabular}

${ }^{*}$ Refer to values in Figure 1

The forecasting results for both container sizes after intervention were closer to the actual demand data than the forecast of the non-adjusted demand data, as shown in Figure 4. The forecast of the adjusted demand data of the 20-feet containers exhibited a lower forecasting error than that of the non-adjusted demand, which was expected to represent the real demand conditions from 2018. Likewise, the results for the 40 -feet containers showed a similar pattern as the 20 -feet containers. In summary, the forecasts for the adjusted demand data for both container sizes were more accurate than the forecasts of the non-adjusted demand data.

In our case study, the forecast accuracy could increase by about $40 \%$ whereas, in Khamphinit and Ongkunaruk (2016), forecast accuracy increased by about $22 \%$ to $56 \%$ when implementing the time series with intervention. Therefore, it is recommended the company use a combination of qualitative and time series forecasting to predict the monthly demand for containers. 


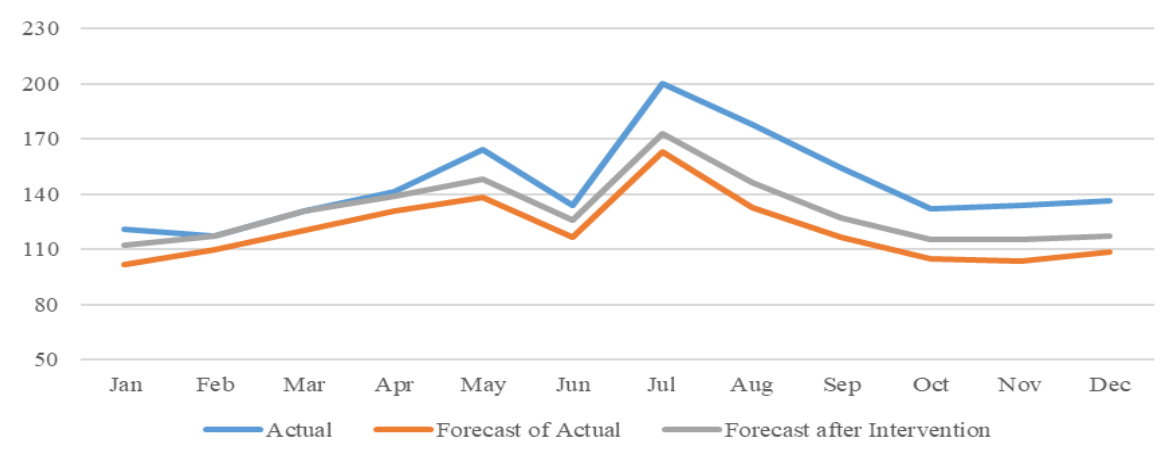

(a)

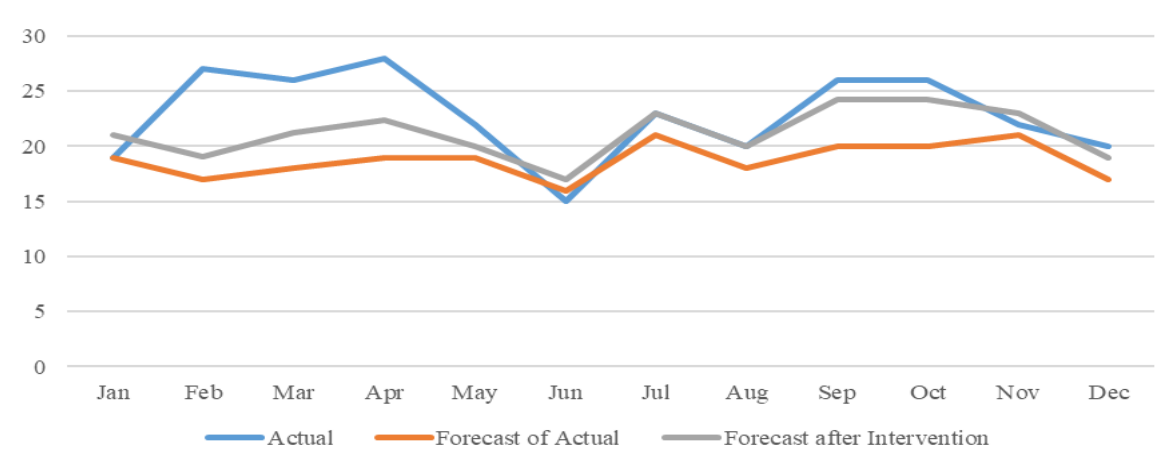

(b)

Figure 4 Comparison of the non-adjusted demand and demand forecast of: (a) 20-feet; and (b) 40feet reefer containers with the results of forecasting after intervention

\section{Conclusions}

The findings showed that the MAPE values from the intervention forecasting approaches outperformed the traditional time series approach in this particular case. Specifically, the intervention forecasting approach revealed benefits such as having data adjusted by human insight twice. The first data adjustment acted as "a screening tool" to identify and correct all irregular demand points prior to feeding this "cleaned" data into the quantitative calculation. This step helped avoid the "garbage in/garbage out" phenomenon. The second intervention adjustment from experts acted as a "reality check tool", which put human's insights back into the result from the mathematical models. Again, this step was comparable to the seasonality index concept in time series forecasting, which adds a seasonal characteristic back to de-seasonalized forecast demand to represent the reality of each season. While the seasonal index might have static pattern the intervention by expert is more event-specific and more intuitive. Given that the reefer demand forecast is very sensitive to any weekly or even daily events, we can conclude that the combination of human insight from the qualitative method and mathematical precision from the quantitative method helped increase its forecasting accuracy. Overall, with more reliable forecasting, container procurement officers can then enhance both their circulation efficiency and customer service levels.

In regard to the impact of different product categories, the intervention forecasting method also yielded very similar results for both the 20- and 40-feet containers. For both container sizes, non-adjusted demand exhibited a higher forecast error than the adjusted demand for both sizes. As a result, the adjustment forecast helped increase the forecast accuracy by $42.39 \%$ and $39.42 \%$ for the 20 - and 40 -feet containers, respectively.

For implementation purposes, irregular events can be defined as repeatable or nonrepeatable. Non-repeatable events can be disregarded as outliers, since they occur 
accidentally; however, repeatable events should be investigated further since they might happen again in a cyclical manner or should be included in associated forecasting models (e.g. regression). For example, natural disasters and subsidized projects from the government impact only impact forecast errors once, since such events tend not to occur in the future; however, irregular events, such as Ramadhan, in this case, will occur again. Thus, these social events should be systematically recognized and integrated into decisions to improve forecasting accuracy.

It is important to note that data limitations existed in this study, such as, for example, a lack of available quantitative data prior to 2016 as well as only having a single expert to provide insights on the qualitative side. In order to gain more power to apply these findings to other cases, repetitive research or longitudinal research is required. In addition, future research could be extended for comparison against other product categories, comparisons of different product life cycles, or comparisons with other forecasting methods, such as ANN or the regression method (Jaipuria and Mahapatra, 2014; Dhini et al., 2015).

\section{Acknowledgments}

The authors would like to thank the company for kindly providing information for this research. Also, we thank the anonymous reviewers who gave significant suggestions to help us improve our manuscript.

\section{References}

Arvan, M., Fahimnia, B., Reisi, M., Siemsen, E., 2019. Integrating Human Judgement into Quantitative Forecasting Methods: A Review. Omega, Volume 86, pp. 237-252

Box, G.E.P., Jenkins, G.M., Reinsel, G.C., Ljung, G.M., 2008. Time Series Analysis: Forecasting and Control. $4^{\text {th }}$ Edition. Hoboken, New Jersey: John Wiley \& Sons, Inc

BPS-Statistics Indonesia, 2018. Sea Transportation Statistics 2018. CV Dharma Putra, Jakarta, Indonesia

Chong, A.Y.L., Ch'ng, E., Liu, M.J., Li, B., 2017. Predicting Consumer Product Demands via Big Data: The Roles of Online Promotional Marketing and Online Reviews. International Journal of Production Research, Volume 55(17), pp. 5142-5156

Davydenko, A., Fildes, R., 2013. Measuring Forecasting Accuracy: The Case of Judgmental Adjustments to SKU-Level Demand Forecasts. International Journal of Forecasting, Volume 29(3), pp. 510-522

Dhini, A., Surjandari, I., Riefqi, M., Puspasari, M.A., 2015. Forecasting Analysis of Consumer Goods Demand using Neural Networks and ARIMA. International Journal of Technology, Volume 6(5), pp. 872-880

Diaz, R., Talley, W., Tulpule, M., 2011. Forecasting Empty Container Volumes. The Asian Journal of Shipping and Logistics, Volume 27(2), pp. 217-236

Epstein, R., Neely, A., Weintraub, A., Valenzuela, F., Hurtado, S., Gonzalez, G., Beiza, A., Naveas, M., Infante, F., Alarcon, F., Angulo, G, Berner, C, Catalan, J, Gonzalez, C, Yung, D., 2012. A Strategic Empty Container Logistics Optimization in a Major Shipping Company. International Journal of Interfaces, Volume 42(1), pp. 5-16

Farhan, J., Ong, G.P., 2018. Forecasting Seasonal Container Throughput at International Ports using SARIMA Models. Maritime Economics \& Logistics, Volume 20(1), pp. 131148

Fildes, R., Goodwin, P., Onkal, D., 2019. Use and Misuse of Information in Supply Chain Forecasting of Promotion Effects. International Journal of Forecasting, Volume 35(1), pp. $144-156$ 
Gandi, I., 2016. Mitigating High Logistics Cost. In: UN ESCAP Regional Conference for Logistics Service Provider, Jakarta, Indonesia, pp. 49-55

Jaipuria, S., Mahapatra, S.S., 2014. An Improved Demand Forecasting Method to Reduce Bullwhip Effect in Supply Chains. Expert Systems with Applications, Volume 41(5), pp. 2395-2408

Khamphinit, T., Ongkunaruk, P., 2016. Combining Qualitative and Time Series Forecasting to Increase the Forecasting Accuracy for Instant Noodle Sales in Thailand. International Journal of KnE Life Science, Volume 3(3), pp. 1-5

Lubis, H.A., Pantas, V.B., Farda, M., 2019. Demand Forecast of Jakarta-Surabaya High Speed Rail based on Stated Preference Methods. International Journal of Technology, Volume 10(2), pp. 405-416

Meneghini, M., Anzanello, M., Kahmann, A., Tortorella, G.L., 2018. Quantitative Demand Forecasting Adjustment based on Qualitative Factors: Case Study at a Fast Food Restaurant. International Journal of Systems and Management, Volume 13(1), pp. 6880

Min, J., 2008. Forecasting Japanese Tourism Demand in Taiwan using an Intervention Analysis. International Journal of Culture, Tourism, and Hospitality Research, Volume 2(3), pp. 197-216

Mo, L., Xie, L., Jiang, X., Teng, G., Xu, L., Xiao, J., 2018. GMDH-Based Hybrid Model for Container Throughput Forecasting: Selective Combination Forecasting in Nonlinear Subseries. Applied Soft Computing, Volume 62, pp. 478-490

Pradita, S.P., Ongkunaruk, P., 2019. Business Process Analysis and Improvement for a Third Party Logistics Provider in Indonesian Cold Chain Logistics. In: IOP Conference Series: Materials Science and Engineering, Volume 526

Talib, A., 2017. Tuna and Skipjack (A Management Review of Potential Resources in Indonesian Fisheries). Journal of Agribusiness and Fisheries, Volume 10(1), pp. 38-50

Tang, S., Xu, S., Gao, J., 2019. An Optimal Model based on Multifactors for Container Throughput Forecasting. KSCE Journal of Civil Engineering, Volume 23(9), pp. 41244131

Tangkham, K., Ongkunaruk, P., 2019. Business Process Analysis for a Container Depot Service Provider in Thailand, 2019. In: International Conference on Engineering, Science, and Industrial Applications (ICESI), Tokyo, Japan, pp. 1-5

Taylor, S.J., Letham, B., 2017. Forecasting at Scale. The American Statistician, Volume 72(1), pp. 37-45

Trapero, J.R., Kourentzes, N., Fildes, R., 2015. On the Identification of Sales Forecasting Models in the Presence of Promotions. Journal of Operational Research Society, Volume 66(2), pp. 299-307

Wang, Y., Meng, Q., 2019. Integrated Method for Forecasting Container Slot Booking in Intercontinental Liner Shipping Service. Flexible Services and Manufacturing Journal, Volume 31(3), pp. 653-674 